\title{
Improved multiplex PCR primers for rapid identification of coagulase-negative staphylococci
}

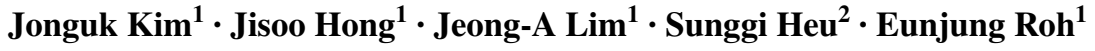

Received: 7 July 2016 / Revised: 13 July 2017 / Accepted: 25 July 2017 / Published online: 9 August 2017

(C) The Author(s) 2017. This article is an open access publication

\begin{abstract}
Coagulase-negative staphylococci (CNS) are opportunistic pathogens that are currently emerging as causative agents of human disease. Though CNS are widespread in the clinic and food, their precise identification at species level is important. Here, using $16 \mathrm{~S}$ rRNA sequencing, 55 staphylococcal isolates were identified as $S$. capitis, S. caprae, S. epidermidis, S. haemolyticus, S. pasteuri, S. saprophyticus, S. warneri, and S. xylosus. Although $16 \mathrm{~S}$ rRNA sequencing is universally accepted as a standard for bacterial identification, the method did not effectively discriminate closely related species, and additional DNA sequencing was required. The divergence of the $\operatorname{sod} A$ gene sequence is higher than that of $16 \mathrm{~S}$ rRNA. To devise a rapid and accurate identification method, sodA-specific primers were designed to demonstrate that species-specific multiplex polymerase chain reaction (PCR) can be used for the identification of CNS species. The accuracy of this method was higher than that of phenotypic identification; the method is simple and less time-consuming than $16 \mathrm{~S}$ rRNA sequencing. Of the $55 \mathrm{CNS}$ isolates, $92.72 \%$ were resistant to at least one antibiotic, and $60 \%$ were resistant to three or more
\end{abstract}

Communicated by Jorge Membrillo-Hernández.

Electronic supplementary material The online version of this article (doi:10.1007/s00203-017-1415-9) contains supplementary material, which is available to authorized users.

Eunjung Roh rosalia51@ korea.kr

1 Microbial Safety Team, National Institute of Agricultural Sciences, Rural Development Administration, Wanju 55365, Republic of Korea

2 Crop Cultivation and Environment Research Division, National Institute of Crop Science, Rural Development Administration, Suwon 16613, Republic of Korea antibiotics. CNS isolates produced diverse virulence-associated enzymes, including hemolysin (produced by $69.09 \%$ of the isolates), protease (65.45\%), lipase (54.54\%), lecithinase (36.36\%), and DNase (29.09\%); all isolates could form a biofilm. Because of the increasing pathogenic significance of CNS, the efficient multiplex PCR detection method developed in this study may contribute to studies for human health.

Keywords Coagulase-negative staphylococci $\cdot$ Speciesspecific PCR $\cdot \operatorname{sodA} \cdot$ Antimicrobial resistance $\cdot$ Virulence factor

\section{Introduction}

Staphylococci includes coagulase-positive staphylococci (CPS), almost exclusively represented by Staphylococcus aureus, and coagulase-negative staphylococci (CNS) (Becker et al. 2004). To date, the Staphylococcus genus comprises 49 species and 26 subspecies (Han et al. 2015). Most studies on staphylococcal pathogenicity have focused on $S$. aureus, and little attention has been paid to CNS (ChajeckaWierzchowska et al. 2015). CNS have been considered as nonpathogenic; however, they were recently isolated from patients with a weakened immune system and identified as the causative agents of infections caused by contaminated medical equipment and food (Piette and Verschraegen 2009). Most CNS infections occur as a consequence of long-term usage of indwelling medical devices, such as central venous catheters, artificial heart valves, and pace-makers (Chu et al. 2008). Because CNS are found on normal human and animal skin, fresh vegetables can be contaminated by hand contact during harvest or distribution. The foodstuff surface can serve as a vehicle for the transmission of pathogenic bacteria 
capable of causing disease in humans (Maistro et al. 2012; Marino et al. 2011). CNS infections are difficult to control because these bacteria produce biofilms on the surfaces of foreign materials and are resistant to multiple antibiotics (John and Harvin 2007). Biofilm formation increases their antibiotic resistance by about 1000 -fold over that of planktonic bacteria (Donlan 2002). In addition to biofilms, CNS species produce other diverse virulence factors and enzymes, such as hemolysin, lipase, lecithinase, DNase, and protease (Kot et al. 2013). Alarmingly, a significant increase of multidrug-resistant CNS infections is observed (Koksal et al. 2009). Because of the increasing pathogenic significance of CNS, rapid and accurate identification methods are required for the assessment of the pathogenic potential of individual CNS species and for the development of species-specific management strategies.

Various CNS identification methods exist, both phenotypic and genotypic. Many different types of manual and automated tests have been developed for the identification of CNS species based on their phenotypic characteristics. These include the API Staph test, Staph-Zym test, and BD Phoenix Automated Microbiology System (Aldea-Mansilla 2006; Cirkovic et al. 2008); however, the accuracy of these methods is low, 50-70\% (Koop et al. 2012). Recently, several attempts have been made to identify CNS species using matrix-assisted laser desorption ionization time-of-flight mass spectrometry (MALDI-TOF MS) based on different protein expression profiles (Dupont et al. 2010). However, large variation in the sample treatment methods makes it difficult to identify pathogens in mixed cultures using this procedure. Furthermore, the use of this method is associated with a high initial acquisition cost, which limits its implementation in many laboratories (Tomazi et al. 2014). By comparison, genotypic identification methods based on DNA sequencing are more accurate than the phenotypic tests mentioned above (Bergeron et al. 2011). Amplified fragment length polymorphism fingerprinting (AFLP) (Taponen et al. 2006) is relatively discriminative, but is expensive and labor intensive. Wholegenome DNA-DNA hybridization analysis (Svec et al. 2004) has also been used for the identification of Staphylococcus species. These two methods are not suitable for routine use, and their major disadvantages include sample manipulation after the polymerase chain reaction (PCR) step and the requirement for gene probes, whose preparation may be time-consuming.

Partial 16S rRNA sequencing is widely accepted as a standard method for bacterial identification (Becker et al. 2004). However, in some cases, the method is unable to discriminate between phylogenetically close species (Ghebremedhin et al. 2008). Species identification methods have therefore been developed based on sequencing of other housekeeping genes, including $h s p 60$ (encoding heat shock protein 60) (Goh et al. 1997), gap (glyceraldehyde3-phosphate dehydrogenase) (Yugueros et al. 2000), sodA (superoxide dismutase A) (Poyart et al. 2001), tuf (elongation factor Tu) (Martineau et al. 2001), rpoB ( $\beta$ subunit of RNA polymerase) (Drancourt and Raoult 2002), and dnaJ (chaperone DnaJ) (Shah et al. 2007). Sequence variation within the sodA gene has been widely exploited for the genotypic identification of CNS species (Sivadon et al. 2005). The divergence of the staphylococcal sodA gene is higher than that of 16S rRNA (Poyart et al. 2001); thus this gene has been used as a target in staphylococcal species identification (Iwase et al. 2007). However, these studies require additional processes after the PCR step, such as DNA sequencing and homology comparisons.

In the current study, new primer sets targeting $\operatorname{sodA}$ were employed in species-specific multiplex PCR for rapid and accurate identification of CNS species. Antimicrobial resistance and virulence factors produced by the CNS isolates were also evaluated to investigate their pathogenicity.

\section{Materials and methods}

\section{Isolation of staphylococci}

Staphylococcal isolates $(n=55)$ used in this study were collected from leaf vegetables, including lettuce, perilla leaf, and chicory, from local markets in South Korea. Eight American Type Culture Collection (ATCC) strains were used as reference strains (Table 1). For each sample, $10 \mathrm{~g}$ of leaves was added to $90 \mathrm{~mL}$ of buffered peptone water (Difco, Sparks, MD, USA), homogenized for $60 \mathrm{~s}$ in a stomacher(Interscience, Saint Nom, France) and incubated for $24 \mathrm{~h}$. Samples were cultured on selective Baird-Parker agar (Difco). Staphylococci were randomly isolated based on colony morphology and grown on Tryptic Soy Agar (TSA; Difco) medium at $37{ }^{\circ} \mathrm{C}$.

Table 1 Reference strains used in this study

\begin{tabular}{ll}
\hline Species & Strain \\
\hline S. capitis subsp. capitis & ATCC 27840 \\
S. caprae & ATCC 35538 \\
S. epidermidis & ATCC 14990 \\
S. haemolyticus & ATCC 29970 \\
S. pasteuri & ATCC 51129 \\
S. saprophyticus subsp. saprophyticus & ATCC 15305 \\
S. warneri & ATCC 29885 \\
S. xylosus & ATCC 29971 \\
\hline
\end{tabular}

ATCC American Type Culture Collection 


\section{Identification}

The phenotypic identification of staphylococci was performed based on colony morphology on Baird-Parker agar, Gram staining, and the API Staph test (BioMerieux, Marcyl'Étoile, France). The API Staph test was performed according to the manufacturer's instructions, and the results were interpreted using apiwebTM (https://apiweb.biomerieux. com). The genotypic identification of staphylococci involved sequence analysis of 16S rRNA. The 16S rRNA gene from 55 CNS isolates was PCR-amplified using the universal primers 518F (5'-CCAGCAGCCGCGGTAATACG-3') and 800R (5'-TACCAGGGTATCTAATCC-3').

\section{DNA extraction}

Bacterial cells from $3 \mathrm{~mL}$ overnight cultures were harvested by centrifugation at $3000 \times g$. Harvested cells were resuspended in $0.1 \mathrm{~mL}$ of TE buffer $(10 \mathrm{mM}$ Tris- $\mathrm{HCl}$ and $1 \mathrm{mM}$ EDTA, pH 8.0) containing $5 \mu \mathrm{L}$ of proteinase $\mathrm{K}(20 \mathrm{mg} /$ $\mathrm{mL})$ and $5 \mu \mathrm{L}$ of lysostaphin $(10 \mathrm{mg} / \mathrm{mL})$, and were incubated for $60 \mathrm{~min}$ at $37^{\circ} \mathrm{C}$. Subsequently, $0.1 \mathrm{~mL} 10 \mathrm{mM}$ Tris- $\mathrm{HCl}(\mathrm{pH} 8.0)$ and $60 \mu \mathrm{L}$ of lysozyme $(10 \mathrm{mg} / \mathrm{mL})$ were added, followed by incubation at $37^{\circ} \mathrm{C}$ for $1 \mathrm{~h}$. After pretreatment, the DNA was extracted using a G-spin Genomic DNA Extraction Kit (Intron Biotechnology, Kyungki-Do, South Korea).

\section{Species-specific PCR}

To design species-specific PCR primers, the sequence of the sodA gene from each CNS species was downloaded from GenBank (National Center for Biotechnology Information, Bethesda, MD, USA) and analyzed. Sequences from the following organisms were used: S. capitis (AJ343896), S. caprae (AJ343898), S. haemolyticus (AJ343910), S. pasteuri (AJ343920), S. saprophyticus (AJ343924), S. warneri (AJ343932), and S. xylosus (AJ343933). After comparing the sodA sequences from the seven species, specific regions where the sequences diverged were chosen as candidate primer sequences. In the case of $S$. epidermidis, there was no specific sequence in sodA to discriminate $S$. epidermidis from other species; therefore, primers targeting the gseA gene (encoding endopeptidase A) were used instead (Byrne et al. 2007). After confirming the specificity of these candidates via PCR with genomic DNA from each species as a template, species-specific PCR primer sets were selected. The primer sequences used in this study are shown in Table 2. Seven primer sets targeting the $\operatorname{sod} A$ gene were used to amplify targeted fragments from the seven CNS species ( $S$. capitis, S. caprae, S. haemolyticus, S. pasteuri, S. saprophyticus, S. warneri, and S. xylosus). Purified genomic DNAs from the 55 staphylococcal isolates and reference strains were used in amplification reactions with these primer sets.

Table 2 PCR primers used in this study

\begin{tabular}{|c|c|c|c|c|c|c|c|}
\hline Group & Target microorganism & Target gene & Primer & Sequence $\left(5^{\prime}-3^{\prime}\right)$ & $\begin{array}{l}\text { Ampli- } \\
\text { con size } \\
\text { (bp) }\end{array}$ & $\begin{array}{l}\text { Annealing } \\
\text { temperature } \\
\left({ }^{\circ} \mathrm{C}\right)\end{array}$ & References \\
\hline \multirow[t]{8}{*}{1} & \multirow[t]{2}{*}{ S. xylosus } & \multirow[t]{2}{*}{$\operatorname{sod} A$} & SX297F & $\begin{array}{l}\text { GCAAATCTAGACAGTGTTCCA } \\
\text { GAAAAT }\end{array}$ & \multirow[t]{2}{*}{297} & \multirow[t]{2}{*}{63} & \multirow[t]{2}{*}{ In this study } \\
\hline & & & SX297R & CTTCTGAGTTTGGAGTTAAT & & & \\
\hline & \multirow[t]{2}{*}{ S. pasteuri } & \multirow[t]{2}{*}{$\operatorname{sod} A$} & PA237F & $\begin{array}{l}\text { GCTAATTTAGACAGTGTACCTTCT } \\
\text { G }\end{array}$ & \multirow[t]{2}{*}{237} & \multirow[t]{2}{*}{61} & \multirow[t]{2}{*}{ In this study } \\
\hline & & & PA237R & GCCCGTTATTTACTACTAACCA & & & \\
\hline & \multirow[t]{2}{*}{ S. warneri } & \multirow[t]{2}{*}{$\operatorname{sod} A$} & SW110F & GTAACAAAATTAAATGCAGCTG & \multirow[t]{2}{*}{110} & \multirow[t]{2}{*}{57} & \multirow[t]{2}{*}{ In this study } \\
\hline & & & SW110R & TCTTACTGCAGTTTGAATATCAGA & & & \\
\hline & \multirow[t]{2}{*}{ S. haemolyticus } & \multirow[t]{2}{*}{$\operatorname{sod} A$} & HA54F & $\begin{array}{l}\text { AAACAAACTATGGAAATCCAT } \\
\text { CATG }\end{array}$ & \multirow[t]{2}{*}{54} & \multirow[t]{2}{*}{58} & \multirow[t]{2}{*}{ In this study } \\
\hline & & & HA54R & ATTTGGTAACATACGTGTTGTG & & & \\
\hline \multirow[t]{8}{*}{2} & \multirow[t]{2}{*}{ S. caprae } & \multirow[t]{2}{*}{$\operatorname{sod} A$} & $\mathrm{CR} 252 \mathrm{~F}$ & AATTTAGATAGCGTACCTTTG & \multirow[t]{2}{*}{252} & \multirow[t]{2}{*}{58} & \multirow[t]{2}{*}{ In this study } \\
\hline & & & CR252R & AGTTACGATTTCTAATTGACCGTT & & & \\
\hline & \multirow[t]{2}{*}{ S. epidermidis } & \multirow[t]{2}{*}{ gseA } & Epi F & GGCAAATTTGTGGGTCAAGA & \multirow[t]{2}{*}{194} & \multirow[t]{2}{*}{65} & \multirow[t]{2}{*}{ (Byrne et al. 2007) } \\
\hline & & & Epi R & TGGCTAATGGTTTGTCACCA & & & \\
\hline & \multirow[t]{2}{*}{ S. capitis } & \multirow[t]{2}{*}{$\operatorname{sod} A$} & CT103F & TCAGATATTCAAACTGCAGTACG & \multirow[t]{2}{*}{103} & \multirow[t]{2}{*}{58} & \multirow[t]{2}{*}{ In this study } \\
\hline & & & CT103R & СТАСТTCAССТTTTTCTTCAGA & & & \\
\hline & S. saprophyticus & $\operatorname{sod} A$ & SA52F & TGGACACTTAAACCACTCACTA & 52 & 55 & In this study \\
\hline & & & SA52R & CTTCTGATTTGGAGTTAAT & & & \\
\hline
\end{tabular}


Species-specific PCR primers were evaluated in singleplex PCR mode, and in two groups (vide infra) of multiplex PCR reactions. Primer sets for multiplex PCR were divided based on the target fragment sizes into group 1 ( $S$. haemolyticus, S. pasteuri, S. warneri, and S. xylosus) and group 2 (S. capitis, S. caprae, S. epidermidis, and S. saprophyticus). Group 1 PCR products comprised four sodA gene fragments; group 2 PCR products contained three sodA with one gseA gene fragments. The sizes of all PCR products were noticeably different.

The PCR mixtures contained $50 \mathrm{nM}$ each primer and $0.1 \mu \mathrm{g}$ of genomic DNA. The thermal cycling conditions were as follows: 1 cycle of $5 \mathrm{~min}$ at $95{ }^{\circ} \mathrm{C}$, followed by 30 cycles of $30 \mathrm{~s}$ at $95{ }^{\circ} \mathrm{C}, 30 \mathrm{~s}$ at $55^{\circ} \mathrm{C}$ (group 1 ) or $53{ }^{\circ} \mathrm{C}$ (group 2), and $30 \mathrm{~s}$ at $72{ }^{\circ} \mathrm{C}$. The final step comprised $7 \mathrm{~min}$ at $72{ }^{\circ} \mathrm{C}$. After PCR amplification, $5 \mu \mathrm{L}$ of each reaction mixture was analyzed on a $2 \%$ agarose gel.

\section{Phylogenetic comparison}

The phylogenetic relatedness of staphylococcal species was determined by sequence analysis of $16 \mathrm{~S}$ rRNA and sodA genes. The 16S rRNA and sodA sequences were obtained from GenBank, and phylogenetic trees were constructed using ClustalW. A bootstrap analysis with 100 replicates was conducted to obtain confidence levels for the branches.

\section{Antimicrobial resistance}

Antimicrobial resistance to 19 antibiotics was assessed using the disc diffusion method, in accordance with the standards of the Clinical and Laboratory Standards Institute (CLSI 2014). All isolates were incubated on Tryptic Soy Broth (TSB; Difco) medium at $37^{\circ} \mathrm{C}$, and the optical density (OD) at $600 \mathrm{~nm}$ of cultures was adjusted to 0.5 using a spectrophotometer. Mueller-Hinton agar (MHA; Oxoid, Hampshire, UK) was dispensed onto plastic culture plates to yield a uniform depth of $4 \mathrm{~mm}$. A sterile swab was dipped into the OD-adjusted bacterial suspension and streaked onto the entire MHA surface. After streaking, the inoculum was dried and an antimicrobial disc was applied using a dispenser. The plate was incubated at $37{ }^{\circ} \mathrm{C}$ for $24 \mathrm{~h}$. Nineteen antimicrobial discs containing the following antibiotics were tested: penicillin (10 U), oxacillin $(1 \mu \mathrm{g})$, gentamycin $(10 \mu \mathrm{g})$, amoxicillin/clavulanic acid $(30 \mu \mathrm{g})$, tetracycline $(30 \mu \mathrm{g})$, cephalothin $(30 \mu \mathrm{g})$, imipenem $(10 \mu \mathrm{g})$, ciprofloxacin $(5 \mu \mathrm{g})$, erythromycin $(15 \mu \mathrm{g})$, telithromycin $(15 \mu \mathrm{g})$, clindamycin $(2 \mu \mathrm{g})$, chloramphenicol $(30 \mu \mathrm{g})$, trimethoprim/sulfamethoxazole $(25 \mu \mathrm{g})$, nitrofurantoin $(300 \mu \mathrm{g})$, quinupristin/dalfopristin $(15 \mu \mathrm{g})$, linezolid $(30 \mu \mathrm{g})$, vancomycin $(30 \mu \mathrm{g})$, rifampicin $(5 \mu \mathrm{g})$, and cefoxitin $(30 \mu \mathrm{g})$. All of the applied antibiotic disc plates were incubated at $37^{\circ} \mathrm{C}$ for $24 \mathrm{~h}$. S. aureus ATCC 25923 was used as the control.

\section{Production of virulence factors}

The presence of bacterial virulence factors was analyzed as follows. Hemolytic activity was determined on plates with a blood agar base with $5 \%(\mathrm{v} / \mathrm{v})$ sheep blood at $37{ }^{\circ} \mathrm{C}$ for $24 \mathrm{~h}$. The formation of hemolysis zones around the colonies indicated a positive result. Lipolytic activity was estimated by streaking the isolates onto Tween 20 agar (10 $\mathrm{g}$ of peptone, $5 \mathrm{~g}$ of $\mathrm{NaCl}, 0.1 \mathrm{~g}$ of $\mathrm{CaCl}_{2}, 20 \mathrm{~g}$ of agar, and $1 \mathrm{~mL}$ of Tween 20 per liter) and incubating at $37^{\circ} \mathrm{C}$ for $24 \mathrm{~h}$. The formation of an opaque halo around the colonies indicated a positive result. Proteolytic activity was assessed by inoculating the isolates onto modified TSA medium containing $1 \%$ skim milk and incubating at $37{ }^{\circ} \mathrm{C}$ for $24 \mathrm{~h}$. A positive result was indicated by the formation of a halo around the colonies. DNase activity was determined by inoculating the isolates onto DNase agar containing the methyl green indicator dye (Oxoid). The plates were incubated for $24 \mathrm{~h}$ at $37{ }^{\circ} \mathrm{C}$ and examined for evidence of DNA hydrolysis. A positive result was indicated by the formation of a clear zone around the colonies.

To determine their ability to form a biofilm, the staphylococcal isolates were transferred to TSB medium and incubated at $37{ }^{\circ} \mathrm{C}$ for $18 \mathrm{~h}$. A 1:100 dilution of the cultures was transferred to a 96-well polystyrene plate (SPL, Gyeonggido, South Korea) and incubated at $37^{\circ} \mathrm{C}$ for $18 \mathrm{~h}$. Following the incubation, the supernatant was removed and the formed biofilms were carefully washed with physiological saline to remove planktonic bacteria. The biofilms were dried at $60{ }^{\circ} \mathrm{C}$ for $30 \mathrm{~min}$ and stained with $1 \%(\mathrm{w} / \mathrm{v})$ crystal violet for $30 \mathrm{~min}$. Unbound crystal violet was then removed with physiological saline until the control well became colorless. Bound crystal violet in each well was solubilized with 33\% (v/v) glacial acetic acid, and sample absorbance was measured at OD $570 \mathrm{~nm}$ using a microplate reader (PerkinElmer, Waltham, MA, USA). The biofilm-forming ability was classified according to absorbance at OD $570 \mathrm{~nm}$ as weak (A570 $<0.40$ ), moderate $(0.40<$ A570 $<0.80$ ), or strong (A570 $>0.80$ ).

The enzymatic experiments and biofilm assays were repeated twice, with three replicates per experiment.

\section{Results and discussion}

\section{Improvement of CNS identification methods}

To investigate the prevalence of pathogenic CNS on leaf vegetables, presumptive staphylococcal species were isolated on a selective medium, Baird-Parker agar. In total, 55 bacterial colonies were randomly selected and identified as follows. 
Table 3 Comparison of phenotypic and genotypic identification results

\begin{tabular}{|c|c|c|c|c|}
\hline Strain & $16 \mathrm{~S}$ rRNA & $\begin{array}{l}\text { Species-specific } \\
\text { PCR }\end{array}$ & API Staph & HV \\
\hline S-37 & S. capitis & S. capitis & S. capitis & 63.30 \\
\hline S-182 & S. capitis & S. capitis & S. capitis & 99.10 \\
\hline S-185 & S. capitis & S. capitis & S. capitis & 96.00 \\
\hline S-72 & S. caprae & S. caprae & S. caprae & 65.50 \\
\hline S-176 & S. caprae & S. caprae & S. caprae & 97.00 \\
\hline S-4 & S. epidermidis & S. epidermidis & S. epidermidis & 89.30 \\
\hline S-5 & S. epidermidis & S. epidermidis & S. epidermidis & 97.90 \\
\hline S-9 & S. epidermidis & S. epidermidis & S. epidermidis & 99.40 \\
\hline S-10 & S. epidermidis & S. epidermidis & S. epidermidis & 99.40 \\
\hline$S-11$ & S. epidermidis & S. epidermidis & S. epidermidis & 99.40 \\
\hline S-12 & S. epidermidis & S. epidermidis & S. epidermidis & 99.40 \\
\hline S-13 & S. epidermidis & S. epidermidis & S. epidermidis & 99.40 \\
\hline S-62 & S. epidermidis & S. epidermidis & S. epidermidis & 97.90 \\
\hline S-65 & S. epidermidis & S. epidermidis & S. epidermidis & 94.30 \\
\hline S-88 & S. epidermidis & S. epidermidis & S. epidermidis & 88.10 \\
\hline S-104 & S. epidermidis & S. epidermidis & S. epidermidis & 99.40 \\
\hline S-105 & S. epidermidis & S. epidermidis & S. epidermidis & 86.20 \\
\hline S-115 & S. epidermidis & S. epidermidis & S. epidermidis & 94.60 \\
\hline S-118 & S. epidermidis & S. epidermidis & S. epidermidis & 94.30 \\
\hline S-180 & S. epidermidis & S. epidermidis & S. epidermidis & 97.30 \\
\hline S-181 & S. epidermidis & S. epidermidis & S. epidermidis & 97.30 \\
\hline S-183 & S. epidermidis & S. epidermidis & S. epidermidis & 94.30 \\
\hline SS-23 & S. epidermidis & S. epidermidis & S. epidermidis & 97.90 \\
\hline S-8 & S. haemolyticus & S. haemolyticus & S. haemolyticus & 99.00 \\
\hline S-122 & S. haemolyticus & S. haemolyticus & S. haemolyticus & 80.60 \\
\hline S-123 & S. haemolyticus & S. haemolyticus & S. haemolyticus & 92.40 \\
\hline S-124 & S. haemolyticus & S. haemolyticus & S. aureus & 42.20 \\
\hline S-166 & S. haemolyticus & S. haemolyticus & S. haemolyticus & 87.00 \\
\hline S-167 & S. haemolyticus & S. haemolyticus & S. haemolyticus & 87.00 \\
\hline SS-13 & S. haemolyticus & S. haemolyticus & S. haemolyticus & 99.60 \\
\hline S-34 & S. pasteuri & S. pasteuri & S. simulans & 72.60 \\
\hline S-35 & S. pasteuri & S. pasteuri & S. simulans & 95.40 \\
\hline SS-1 & S. pasteuri & S. pasteuri & S. warneri & 46.80 \\
\hline SS-32 & S. pasteuri & S. pasteuri & S. warneri & 46.80 \\
\hline S-68 & S. saprophyticus & S. saprophyticus & S. saprophyticus & 96.30 \\
\hline S-98 & S. saprophyticus & S. saprophyticus & S. xylosus & 99.90 \\
\hline S-38 & S. warneri & S. warneri & S. aureus & 97.80 \\
\hline S-39 & S. warneri & S. warneri & S. xylosus & 99.90 \\
\hline S-66 & S. warneri & S. warneri & S. aureus & 35.80 \\
\hline S-100 & S. warneri & S. warneri & S. xylosus & 71.30 \\
\hline S-142 & S. warneri & S. warneri & S. hominis & 40.40 \\
\hline S-163 & S. warneri & S. warneri & S. warneri & 37.50 \\
\hline S-173 & S. warneri & S. warneri & S. warneri & 89.90 \\
\hline S-174 & S. warneri & S. warneri & S. warneri & 55.80 \\
\hline S-208 & S. warneri & S. warneri & S. warneri & 55.80 \\
\hline SS-3 & S. warneri & S. warneri & S. warneri & 89.90 \\
\hline SS-6 & S. warneri & S. warneri & S. warneri & 89.90 \\
\hline S-169 & S. xylosus & S. xylosus & S. xylosus & 99.70 \\
\hline
\end{tabular}

Table 3 (continued)

\begin{tabular}{lllll}
\hline Strain & 16S rRNA & $\begin{array}{l}\text { Species-specific } \\
\text { PCR }\end{array}$ & API Staph & HV \\
\hline S-170 & S. xylosus & S. xylosus & S. xylosus & 99.70 \\
S-171 & S. xylosus & S. xylosus & S. xylosus & 99.70 \\
S-172 & S. xylosus & S. xylosus & S. xylosus & 99.70 \\
S-179 & S. xylosus & S. xylosus & S. xylosus & 99.70 \\
SS-17 & S. xylosus & S. xylosus & S. xylosus & 99.90 \\
SS-19 & S. xylosus & S. xylosus & S. xylosus & 99.70 \\
SS-20 & S. xylosus & S. xylosus & S. xylosus & 99.70 \\
\hline
\end{tabular}

$H V$ homology value in percent (\%) of API Staph

First, the API Staph test was used to identify the isolated staphylococcal species. This commercially available phenotypic identification system is based on biochemical reactions, is simple to use, and provides rapid results. All isolates were identified as staphylococci: three were $S$. aureus and the remaining 52 belonged to nine CNS species ( $S$. capitis, S. caprae, S. epidermidis, S. haemolyticus, S. hominis, S. pasteuri, S. saprophyticus, S. warneri, and S. xylosus) (Table 3). Based on the recommendation of the API software, $80 \%$ homology with the API ID (\% ID) was chosen as the high-probability cutoff for positive identification (Park et al. 2011); however, the analysis of ca. $20 \%$ of the isolates $(12 / 55)$ resulted in low-probability species identification (\% ID $<80)$.

In addition to the API kit, several phenotypic systems based on colony characteristics, antibiotyping patterns, saccharide utilization, and enzyme production are available for rapid and accurate identification of staphylococci (Aldea-Mansilla 2006). However, these diagnostic systems are considered to be a primary means for staphylococcal identification as their ability to provide reliable results is limited, mainly because of phenotypic differences between strains of the same species (Kooken et al. 2014).

Next, 16S rRNA sequencing was used to identify the bacterial isolates. All isolates were identified as CNS species, sharing $98-100 \%$ homology with the type strains; the sequences were deposited in GenBank under the accession numbers KX946134-KX946188. Homology values above $98 \%$ are considered as reliable; thus the identification results were credible. The isolates were identified as $S$. capitis $(n=3), S$. caprae $(n=2), S$. epidermidis $(n=18), S$. haemolyticus $(n=7)$, S. pasteuri $(n=4)$, S. saprophyticus $(n=2), S$. warneri $(n=11)$, and S. xylosus $(n=8)$ (Table 3$)$. The identification of $44(80 \%)$ CNS isolates matched the identification by API Staph analysis. The ID values of four isolates from the remaining $11(20 \%)$ isolates misidentified by the API kit were greater than $95.4 \%$. These results show that, in terms of homology values, $16 \mathrm{~S}$ rRNA analysis is superior to the API Staph test. 
Although 16S rRNA analysis is a widely accepted method of bacterial species identification, it is unable to discriminate between closely related species. For example, in a previous study, $S$. capitis was misidentified as $S$. epidermidis, and $S$. xylosus was misidentified as either $S$. cohnii or $S$. saprophyticus (Ghebremedhin et al. 2008; Taponen et al. 2006). Accordingly, many kinds of highly conserved gene sequencing for CNS identification have been developed, including hsp60, gap, sodA, tuf, rpoB, and dnaJ; however, gene sequencing is time-consuming. The reliability of multiplex PCR targeting the conserved genes is same as that of gene sequencing, but the former method is simpler to employ and is more rapid (Blaiotta et al. 2004).

We performed species-specific PCR using primers targeting the sodA gene, which encodes manganese-dependent superoxide dismutase, a key enzyme of oxygen defense systems (Fridovich 1995). In this study, seven new primer sets specifically targeting sodA from seven CNS species ( $S$. capitis, S. caprae, S. haemolyticus, S. pasteuri, S. saprophyticus, $S$. warneri, and $S$. xylosus) were designed and evaluated (Table 2). Each primer set was designed to bind specifically to its target gene (Fig. S1), and not to those of other species (data not shown). S. aureus R0001 and the Escherichia coli DH5 $\alpha$ were used as negative controls and were not detected by any PCR primer set. As shown in Table 3, all isolates were identified as CNS species, consistent with the results of $16 \mathrm{~S}$ rRNA analysis. To compare the accuracy of $16 \mathrm{~S}$ rRNA sequencing and sodA-targeting PCR, ClustalW phylogenetic trees were constructed with
16S rRNA and sodA sequences from eight type strains. The results indicated a higher divergence of the staphylococcal sodA gene than of 16S rRNA (Fig. 1). To increase the efficiency of detection, multiplex PCR assays were set up in two groups. In each multiplex PCR assay, a mixture of DNA from four CNS species yielded four PCR product bands of the expected sizes after gel electrophoresis (Fig. 2).

Previous studies have used $\operatorname{sod} A$ as a target for the identification of staphylococcal species (Iwase et al. 2007; Kooken et al. 2014; Poyart et al. 2001). However, in the majority of these studies, additional steps following PCR, such as sequencing and homology comparisons, were required (Coton et al. 2010). In some studies where $\operatorname{sod} A$ was used as the target gene for species-specific PCR, gel electrophoresis was also used for the identification of species, without any additional steps: $S$. carnosus, $S$. simulans (Blaiotta et al. 2005), S. equorum (Blaiotta et al. 2004), and S. hyicus (Voytenko et al. 2006). However, those studies were reported singleplex PCR method for CNS identification. In the current study, two groups of multiplex PCR primer sets that could discriminate eight CNS species were evaluated. Compared with conserved gene sequencing, species-specific multiplex PCR is more economical because it requires less time, with lower cost, without killing the reliability of identification. Furthermore, identification based on the sodA gene sequence can be extended to Staphylococcus species other than the seven CNS species evaluated in this study.
Fig. 1 Phylogenetic tree construction using the Clustal W method based on $16 \mathrm{~S}$ rRNA sequences (a), and $\operatorname{sod} A$ sequences of eight CNS species (b) obtained from GenBank. The value on each branch is the occurrence of the branching order in 100 bootstrapped trees. The scale bar represents $1 \%$ differences in nucleotide sequences
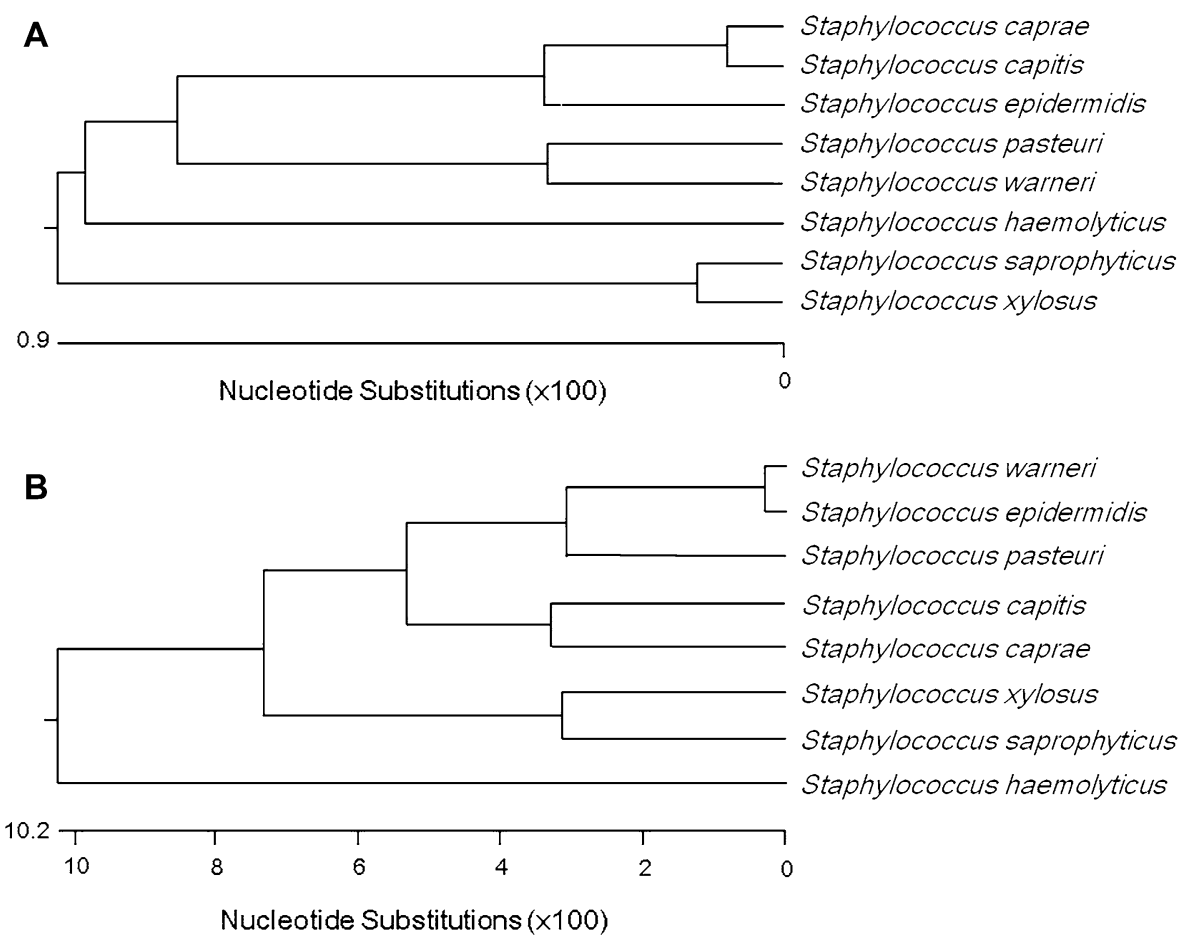


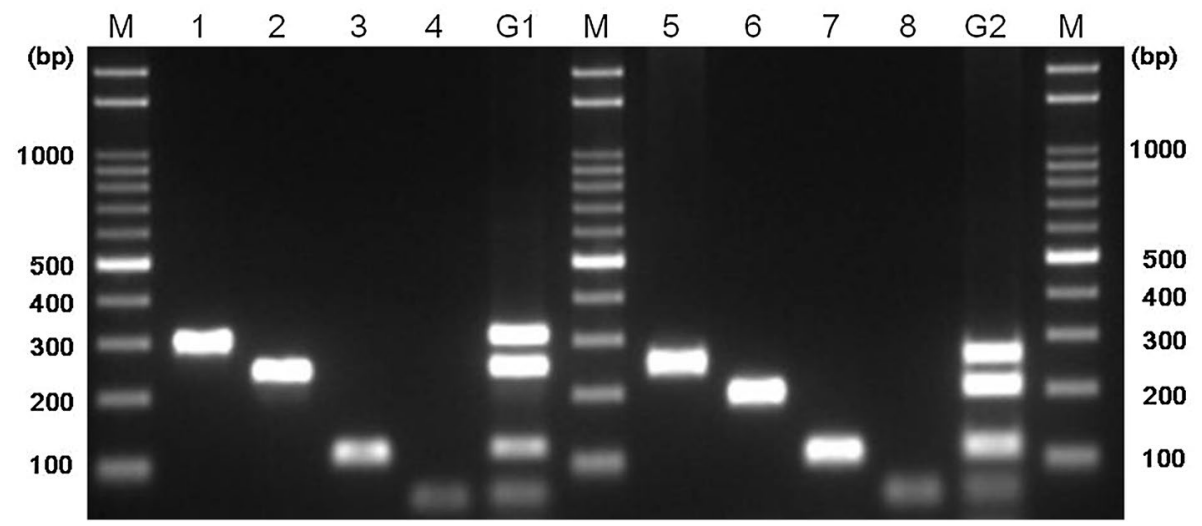

Fig. 2 Agarose gel electrophoresis of PCR amplicons after amplification of species-specific singleplex and multiplex PCR targeting sodA gene from eight CNS species. Lanes $M$ size marker; $1, S$. xylosus; 2, S. pasteuri; 3, S. warneri; 4, S. haemolyticus, G1: group 1 ( .

\section{Antimicrobial resistance of CNS}

CNS are commonly found in food, environment, and clinical setting (Huber et al. 2011), and were recently recognized as etiologic agents of animal and human infectious diseases (Tremblay et al. 2014). Antimicrobial resistance is an important virulence factor (Wang et al. 2006), but little information is available on the prevalence of antimicrobial resistance in CNS from leaf vegetables. Antimicrobial resistance of CNS isolates was therefore examined in the current study. The distribution of resistance to 19 antimicrobial agents is presented in Table 4: $92.72 \%$ of the CNS isolates $(51 / 55)$ showed resistance to at least one antimicrobial agent (Table 4); $83.64 \%$ of the CNS isolates (46/55) showed multidrug resistance. $S$. haemolyticus isolates were resistant to a lot more antibiotics than other CNS isolates. S. haemolyticus, the second most frequently isolated CNS from nosocomial infections, is resistant to multiple antibiotics (Brzychczy-Wloch et al. 2013). In the current study, resistance to penicillin, erythromycin, and oxacillin was frequently observed in the resistant isolates, but none of them were resistant to nitrofurantoin.

\section{CNS virulence factors}

Pathogenicity of staphylococci is linked to the production of virulence-associated enzymes that are responsible for the development of disease (Taponen and Pyorala 2009). Various virulence factors have been identified in $S$. aureus strains from diverse sources (Kim et al. 2015); however, little is known about the virulence factors produced by CNS. The CNS strains isolated in the current study produced diverse virulence-associated enzymes, including hemolysin $(69.09 \%)$, protease $(65.45 \%)$, lipase $(54.54 \%)$, xylosus, S. pasteuri, S. warneri, and S. haemolyticus); 5, S. caprae; 6, S. epidermidis; 7, S. capitis; 8, S. saprophyticus, G2: group 2 (S. caprae, S. epidermidis, S. capitis, and S. saprophyticus)

lecithinase (36.36\%), and DNase $(29.09 \%)$ (Table 4). Notably, all species produced hemolysin. Previous studies revealed that staphylococcal hemolysin plays a specific role in the pathogenesis of various infectious diseases, such as neurotoxia and peritonitis. The consumption of fresh vegetables contaminated with CNS may therefore lead to human illness (Dahlberg et al. 2015).

In addition to virulence-associated enzymes, it has been proposed that CNS biofilms are an important cause of recurrent and chronic infectious diseases in animals (Oliveira et al. 2006). Biofilm-associated bacteria are highly adhesive and exhibit decreased susceptibility to detergents, biocides, and antimicrobial agents (Donlan 2001). The biofilms therefore significantly increase the ability of bacteria to dwell in tissues and on inanimate surfaces. In the current study, biofilm formation by the CNS isolates was investigated by crystal violet staining. Based on this assay, the biofilm-forming ability of the CNS isolates was classified as weak, moderate, or strong. From the 55 isolates, the biofilm-forming ability of $9(16.36 \%)$, $36(65.45 \%)$, and $10(18.18 \%)$ isolates was classified as weak, moderate, and strong, respectively (Table 4). On the species level, the biofilm-forming ability was most pronounced in S. haemolyticus and S. xylosus. S. haemolyticus can cause serious infection in humans, leading to endocarditis, urinary tract infections, and septicemia (Piette and Verschraegen 2009). Although S. xylosus is not commonly associated with human infection, it has been isolated in some cases of endocarditis, pyelonephritis, and septicemia (Gozalo et al. 2010). The presence of multidrug-resistant CNS with biofilm-forming ability on fresh vegetables is concerning. Because some CNS species are more resistant to antibiotics than other species, their identification on a species level is important for the control of CNS infections. 
Table 4 Antimicrobial resistance and virulence enzyme production

\begin{tabular}{|c|c|c|c|c|c|c|c|c|}
\hline Species & Strain & Antibiotics & Hemolysin & Lipase & Lecithinase & DNase & Protease & $\begin{array}{l}\text { Biofilm } \\
\text { formation }^{\text {a }}\end{array}$ \\
\hline S. capitis & S-37 & E, CIP, DA & $\bigcirc^{b}$ & $-{ }^{\mathrm{b}}$ & - & $\bigcirc$ & & +++ \\
\hline S. capitis & S-182 & P, CIP, AMC & & - & - & $\bigcirc$ & & +++ \\
\hline S. capitis & S-185 & - & $\bigcirc$ & - & - & $\bigcirc$ & & +++ \\
\hline S. caprae & S-72 & $\mathrm{E}$ & & - & $\bigcirc$ & $\bigcirc$ & & ++ \\
\hline S. caprae & S-176 & - & O & - & $\bigcirc$ & $\bigcirc$ & & ++ \\
\hline S. epidermidis & S-4 & $\mathrm{P}, \mathrm{CN}, \mathrm{E}, \mathrm{OX}, \mathrm{FOX}, \mathrm{IPM}$ & $\bigcirc$ & $\bigcirc$ & - & - & ) & ++ \\
\hline S. epidermidis & S-5 & $\mathrm{P}, \mathrm{CN}, \mathrm{E}, \mathrm{OX}, \mathrm{FOX}, \mathrm{TE}, \mathrm{DA}, \mathrm{VA}$ & $\bigcirc$ & $\bigcirc$ & $\bigcirc$ & - & $\bigcirc$ & + \\
\hline S. epidermidis & S-9 & $\mathrm{P}$ & - & $\bigcirc$ & - & $\bigcirc$ & $\bigcirc$ & + \\
\hline S. epidermidis & S-10 & $\mathrm{P}$ & - & 0 & - & - & 0 & + \\
\hline S. epidermidis & S-11 & $\mathrm{P}, \mathrm{QD}$ & - & $\bigcirc$ & - & - & $\bigcirc$ & ++ \\
\hline S. epidermidis & S-12 & $\mathrm{P}, \mathrm{OX}, \mathrm{LZD}$ & - & 0 & - & - & $\bigcirc$ & ++ \\
\hline S. epidermidis & S-13 & $\mathrm{P}, \mathrm{CN}, \mathrm{OX}$ & 0 & 0 & - & - & 0 & + \\
\hline S. epidermidis & $S-62$ & CIP & & $\bigcirc$ & - & $\bigcirc$ & $\bigcirc$ & ++ \\
\hline S. epidermidis & S-65 & $\mathrm{P}, \mathrm{E}$ & & 0 & - & 0 & $\bigcirc$ & ++ \\
\hline S. epidermidis & S-88 & - & 0 & - & - & 0 & - & + \\
\hline S. epidermidis & S-104 & $\mathrm{C}, \mathrm{QD}$ & - & 0 & - & - & $\bigcirc$ & ++ \\
\hline S. epidermidis & S-105 & $\mathrm{P}, \mathrm{OX}, \mathrm{LZD}$ & - & $\bigcirc$ & - & - & 0 & + \\
\hline S. epidermidis & S-115 & $\mathrm{P}, \mathrm{QD}$ & 0 & $\bigcirc$ & - & - & $\bigcirc$ & ++ \\
\hline S. epidermidis & S-118 & $\mathrm{P}, \mathrm{E}, \mathrm{AMC}$ & - & 0 & - & - & $\bigcirc$ & ++ \\
\hline S. epidermidis & S-180 & P, E, OX, FOX & & $\bigcirc$ & - & - & 0 & ++ \\
\hline S. epidermidis & S-181 & $\mathrm{P}, \mathrm{E}, \mathrm{OX}, \mathrm{FOX}, \mathrm{IPM}$ & & $\bigcirc$ & $\bigcirc$ & - & $\bigcirc$ & ++ \\
\hline S. epidermidis & S-183 & CIP, DA & & $\bigcirc$ & $\bigcirc$ & - & $\bigcirc$ & ++ \\
\hline S. epidermidis & SS-23 & $\mathrm{P}, \mathrm{CN}, \mathrm{QD}$ & & - & - & - & $\bigcirc$ & ++ \\
\hline S. haemolyticus & S-8 & P, CN, E, CIP, TE, LZD & & - & - & - & - & ++ \\
\hline S. haemolyticus & S-122 & $\mathrm{P}, \mathrm{CN}, \mathrm{C}, \mathrm{RD}$ & & - & - & - & $\bigcirc$ & +++ \\
\hline S. haemolyticus & S-123 & $\mathrm{P}, \mathrm{CN}, \mathrm{E}, \mathrm{OX}, \mathrm{FOX}, \mathrm{C}, \mathrm{CIP}$ & & - & - & $\bigcirc$ & $\bigcirc$ & ++ \\
\hline S. haemolyticus & S-124 & $\mathrm{P}, \mathrm{CN}, \mathrm{E}, \mathrm{OX}, \mathrm{FOX}, \mathrm{C}, \mathrm{CIP}, \mathrm{DA}$ & & - & - & - & $\bigcirc$ & +++ \\
\hline S. haemolyticus & S-166 & $\mathrm{P}, \mathrm{CN}, \mathrm{OX}, \mathrm{FOX}, \mathrm{C}, \mathrm{CIP}, \mathrm{DA}$ & & - & - & - & - & +++ \\
\hline S. haemolyticus & S-167 & $\mathrm{P}, \mathrm{OX}, \mathrm{FOX}, \mathrm{KF}$ & & - & $\bigcirc$ & $\bigcirc$ & - & +++ \\
\hline S. haemolyticus & SS-13 & $\mathrm{P}, \mathrm{CN}, \mathrm{E}, \mathrm{OX}, \mathrm{FOX}, \mathrm{C}, \mathrm{CIP}$ & & - & $\bigcirc$ & $\bigcirc$ & $\bigcirc$ & ++ \\
\hline S. pasteuri & S-34 & P, E, C & & - & - & - & - & ++ \\
\hline S. pasteuri & S-35 & $\mathrm{P}, \mathrm{E}$ & & - & - & - & - & ++ \\
\hline S. pasteuri & SS-1 & $\mathrm{P}, \mathrm{CN}, \mathrm{E}, \mathrm{AMC}$ & $\bigcirc$ & - & - & - & - & ++ \\
\hline S. pasteuri & SS-32 & $\mathrm{P}, \mathrm{CN}, \mathrm{E}$ & - & - & - & - & - & ++ \\
\hline S. saprophyticus & S-68 & E, OX, TE, RD & $\bigcirc$ & - & - & - & - & + \\
\hline S. saprophyticus & S-98 & E, OX, FOX & - & - & - & - & - & ++ \\
\hline S. warneri & S-38 & $\mathrm{P}, \mathrm{CN}, \mathrm{E}, \mathrm{C}, \mathrm{TE}, \mathrm{KF}$ & $\bigcirc$ & $\bigcirc$ & $\bigcirc$ & - & $\bigcirc$ & ++ \\
\hline S. warneri & S-39 & $\mathrm{P}, \mathrm{E}, \mathrm{OX}, \mathrm{FOX}, \mathrm{CIP}, \mathrm{KF}$ & $\bigcirc$ & $\bigcirc$ & $\bigcirc$ & - & - & ++ \\
\hline S. warneri & S-66 & $\mathrm{P}, \mathrm{CN}, \mathrm{E}, \mathrm{CIP}, \mathrm{DA}, \mathrm{KF}$ & - & - & $\bigcirc$ & - & - & ++ \\
\hline S. warneri & S-100 & - & D & $\bigcirc$ & $\bigcirc$ & - & - & ++ \\
\hline S. warneri & S-142 & $\mathrm{P}, \mathrm{CN}, \mathrm{OX}, \mathrm{DA}$ & & $\bigcirc$ & - & - & $\bigcirc$ & ++ \\
\hline S. warneri & S-163 & $\mathrm{P}, \mathrm{CN}, \mathrm{VA}$ & & $\bigcirc$ & - & - & $\bigcirc$ & + \\
\hline S. warneri & S-173 & $\mathrm{P}, \mathrm{CN}, \mathrm{OX}, \mathrm{FOX}, \mathrm{AMC}, \mathrm{KF}$ & ) & - & $\bigcirc$ & $\bigcirc$ & - & ++ \\
\hline S. warneri & S-174 & $\mathrm{P}, \mathrm{CN}, \mathrm{CIP}$ & D & $\bigcirc$ & $\bigcirc$ & - & $\bigcirc$ & + \\
\hline S. warneri & S-208 & P, E, C, DA, AMC, TEL & $\Omega$ & $\bigcirc$ & $\bigcirc$ & - & 0 & ++ \\
\hline S. warneri & SS-3 & $\mathrm{P}, \mathrm{CN}, \mathrm{E}, \mathrm{C}, \mathrm{AMC}$ & $\bigcirc$ & $\bigcirc$ & - & - & - & ++ \\
\hline S. warneri & SS-6 & $\mathrm{P}, \mathrm{CN}, \mathrm{E}, \mathrm{C}, \mathrm{TE}, \mathrm{KF}$ & $\bigcirc$ & $\bigcirc$ & $\bigcirc$ & - & - & + \\
\hline S. xylosus & S-169 & $\mathrm{P}, \mathrm{E}, \mathrm{OX}$ & - & - & - & $\bigcirc$ & - & +++ \\
\hline S. xylosus & S-170 & P, E, OX, FOX, RD & $\bigcirc$ & - & $\bigcirc$ & 0 & $\bigcirc$ & +++ \\
\hline
\end{tabular}


Table 4 (continued)

\begin{tabular}{llllllll}
\hline Species & Strain & Antibiotics & Hemolysin & Lipase & Lecithinase & $\begin{array}{c}\text { DNase } \\
\text { Protease }\end{array}$ & $\begin{array}{l}\text { Biofilm } \\
\text { formation }\end{array}$ \\
\hline S. xylosus & S-171 & P, SXT & - & $\bigcirc$ & $\bigcirc$ & - & $\bigcirc$ \\
S. xylosus & S-172 & P, OX & - & $\bigcirc$ & $\bigcirc$ & - & + \\
S. xylosus & S-179 & P, OX & - & - & $\bigcirc$ & - & - \\
S. xylosus & SS-17 & C, RD & - & $\bigcirc$ & $\bigcirc$ & - & - \\
S. xylosus & SS-19 & P & - & $\bigcirc$ & - & - & $\bigcirc$ \\
S. xylosus & SS-20 & P, OX & - & $\bigcirc$ & - & -+ & + \\
\hline
\end{tabular}

${ }^{a}$ Biofilm formation capacity: + , weak $($ A570 $<0.40) ;++$, moderate $(0.40<$ A570 $<0.80)$; +++, strong $($ A570 $>0.80)$

${ }^{\mathrm{b}}$ Enzyme activity: $\bigcirc$, positive; -, negative

\section{Conclusion}

We designed sodA primers specific to seven CNS species for rapid CNS identification, and confirmed. Using these primers, 55 staphylococcal isolates from leaf vegetables were successfully identified. These primers are also suited to multiplex PCR. The new method has the simplicity of phenotypic identification methods with the accuracy of genotypic identification. This method may also be combined with real-time PCR and DNA chip technology to quantify sodA expression in specific Staphylococcus species. Rapid and accurate CNS identification would allow tracking of the transmission of pathogenic CNS and contribute to the control of antibiotic-resistant CNS.

Acknowledgements This work was supported by a Grant (PJ010921) from the Rural Development Administration, Republic of Korea.

\section{Compliance with ethical standards}

Conflict of interest The authors declare that they have no conflict of interest. The English in this document has been checked by at least two professional editors, both native speakers of English. For a certificate, please see: https://www.bioedit.com/digital_certificate/view/85aba90e fe6423d85dd4d7b75a7ba901f00ab814.

Open Access This article is distributed under the terms of the Creative Commons Attribution 4.0 International License (http://creativecommons.org/licenses/by/4.0/), which permits unrestricted use, distribution, and reproduction in any medium, provided you give appropriate credit to the original author(s) and the source, provide a link to the Creative Commons license, and indicate if changes were made.

\section{References}

Aldea-Mansilla C, Garcia de Viedma D, Cercenado E, Martin-Rabadan P, Marin M, Bouza E (2006) Comparison of phenotypic with genotypic procedures for confirmation of coagulase-negative Staphylococcus catheter-related bloodstream infections. J Clin Microbiol 44:3529-3532. doi:10.1128/JCM.00839-06
Becker K, Harmsen D, Mellmann A, Meier C, Schumann P, Peters G, von Eiff C (2004) Development and evaluation of a qualitycontrolled ribosomal sequence database for 16S ribosomal DNAbased identification of Staphylococcus species. J Clin Microbiol 42:4988-4995

Bergeron M et al (2011) Species identification of staphylococci by amplification and sequencing of the tuf gene compared to the gap gene and by matrix-assisted laser desorption ionization time-offlight mass spectrometry. Eur J Clin Microbiol Infect Dis 30:343354. doi:10.1007/s10096-010-1091-z

Blaiotta G, Ercolini D, Mauriello G, Salzano G, Villani F (2004) Rapid and reliable identification of Staphylococcus equorum by a species-specific PCR assay targeting the sodA gene. Syst Appl Microbiol 27:696-702

Blaiotta G, Casaburi A, Villani F (2005) Identification and differentiation of Staphylococcus carnosus and Staphylococcus simulans by species-specific PCR assays of sodA genes. Syst Appl Microbiol 28:519-526. doi:10.1016/j.syapm.2005.03.007

Brzychczy-Wloch M et al (2013) Prevalence of antibiotic resistance in multi-drug resistant coagulase-negative staphylococci isolated from invasive infection in very low birth weight neonates in two Polish NICUs. Ann Clin Microbiol Antimicrob 12:41. doi:10.1186/1476-0711-12-41

Byrne FJ, Waters SM, Waters PS, Curtin W, Kerin M (2007) Development of a molecular methodology to quantify Staphylococcus epidermidis in surgical washout samples from prosthetic joint replacement surgery. Eur J Orthop Surg Traumatol 17:449-456

Chajecka-Wierzchowska W, Zadernowska A, Nalepa B, Sierpinska M, Laniewska-Trokenheim L (2015) Coagulase-negative staphylococci (CoNS) isolated from ready-to-eat food of animal originphenotypic and genotypic antibiotic resistance. Food Microbiol 46:222-226. doi:10.1016/j.fm.2014.08.001

Chu VH et al (2008) Emergence of coagulase-negative staphylococci as a cause of native valve endocarditis. Clin Infect Dis 46:232-242. doi:10.1086/524666

Cirkovic I, Hauschild T, Jezek P, Dimitrijevic V, Vukovic D, Stepanovic S (2008) Identification and antimicrobial susceptibility testing of Staphylococcus vitulinus by the BD phoenix automated microbiology system. Curr Microbiol 57:158-160. doi:10.1007/ s00284-008-9169-x

CLSI (2014) Performance standards for antimicrobial susceptibility testing; 24th informational supplement. CLSI document M100-S24. Clinical and Laboratory Standards Institute, Wayne, PA, USA

Coton E et al (2010) Biodiversity of coagulase-negative Staphylococci in French cheeses, dry fermented sausages, processing environments and clinical samples. Int J Food Microbiol 137:221-229. doi:10.1016/j.ijfoodmicro.2009.11.023 
Dahlberg D, Mariussen E, Goverud IL, Tonjum T, Maehlen J, Antal EA, Hassel B (2015) Staphylococcal alpha-hemolysin is neurotoxic and causes lysis of brain cells in vivo and in vitro. Neurotoxicology 48:61-67. doi:10.1016/j.neuro.2015.03.001

Donlan RM (2001) Biofilm formation: a clinically relevant microbiological process. Clin Infect Dis 33:1387-1392. doi: $10.1086 / 322972$

Donlan RM (2002) Biofilms: microbial life on surfaces. Emerg Infect Dis 8:881-890. doi:10.3201/eid0809.020063

Drancourt M, Raoult D (2002) rроB gene sequence-based identification of Staphylococcus species. J Clin Microbiol 40:1333-1338

Dupont $\mathrm{C}$ et al (2010) Identification of clinical coagulase-negative staphylococci, isolated in microbiology laboratories, by matrixassisted laser desorption/ionization-time of flight mass spectrometry and two automated systems. Clin Microbiol Infect 16:998-1004. doi:10.1111/j.1469-0691.2009.03036.x

Fridovich I (1995) Superoxide radical and superoxide dismutases. Annu Rev Biochem 64:97-112. doi:10.1146/annurev. bi.64.070195.000525

Ghebremedhin B, Layer F, Konig W, Konig B (2008) Genetic classification and distinguishing of Staphylococcus species based on different partial gap, 16S rRNA, hsp60, rpoB, sodA, and tuf gene sequences. J Clin Microbiol 46:1019-1025. doi:10.1128/ JCM.02058-07

Goh SH, Santucci Z, Kloos WE, Faltyn M, George CG, Driedger D, Hemmingsen SM (1997) Identification of Staphylococcus species and subspecies by the chaperonin 60 gene identification method and reverse checkerboard hybridization. J Clin Microbiol 35:3116-3121

Gozalo AS, Hoffmann VJ, Brinster LR, Elkins WR, Ding L, Holland SM (2010) Spontaneous Staphylococcus xylosus infection in mice deficient in NADPH oxidase and comparison with other laboratory mouse strains. J Am Assoc Lab Anim Sci 49:480-486

Han HW, Chang HC, Hunag AH, Chang TC (2015) Optimization of the score cutoff value for routine identification of Staphylococcus species by matrix-assisted laser desorption ionization-time-offlight mass spectrometry. Diagn Microbiol Infect Dis 83:349-354. doi:10.1016/j.diagmicrobio.2015.08.003

Huber H, Ziegler D, Pfluger V, Vogel G, Zweifel C, Stephan R (2011) Prevalence and characteristics of methicillin-resistant coagulasenegative staphylococci from livestock, chicken carcasses, bulk tank milk, minced meat, and contact persons. BMC Vet Res 7:6

Iwase T, Seki K, Shinji H, Mizunoe Y, Masuda S (2007) Development of a real-time PCR assay for the detection and identification of Staphylococcus capitis, Staphylococcus haemolyticus and Staphylococcus warneri. J Med Microbiol 56:1346-1349

John JF, Harvin AM (2007) History and evolution of antibiotic resistance in coagulase-negative staphylococci: susceptibility profiles of new anti-staphylococcal agents. Ther Clin Risk Manag 3:1143-1152

Kim YJ et al (2015) Molecular characterization, antibiotic resistance, and virulence factors of methicillin-resistant Staphylococcus aureus strains isolated from imported and domestic meat in Korea. Foodborne Pathog Dis 12:390-398. doi:10.1089/fpd.2014.1885

Koksal F, Yasar H, Samasti M (2009) Antibiotic resistance patterns of coagulase-negative staphylococcus strains isolated from blood cultures of septicemic patients in Turkey. Microbiol Res 164:404410. doi:10.1016/j.micres.2007.03.004

Kooken J et al (2014) Identification of staphylococcal species based on variations in protein sequences (mass spectrometry) and DNA sequence ( $\operatorname{sod} A$ microarray). Mol Cell Probes 28:41-50. doi:10.1016/j.mcp.2013.10.003

Koop G et al (2012) Short communication: identification of coagulase-negative Staphylococcus species from goat milk with the API Staph identification test and with transfer RNA-intergenic spacer PCR combined with capillary electrophoresis. J Dairy Sci 95:7200-7205. doi:10.3168/jds.2012-5747

Kot B, Binek T, Piechota M, Wolska KM, Zdunek E, Platkowska K (2013) Virulence factors and ability of staphylococci from bovine milk and the cowshed environment to biofilm formation. Pol J Vet Sci 16:639-645

Maistro LC, Miya NTN, Sant'Ana AS, Pereira JL (2012) Microbiological quality and safety of minimally processed vegetables marketed in Campinas, SP-Brazil, as assessed by traditional and alternative methods. Food Control 28:258-264. doi:10.1016/j. foodcont.2012.05.021

Marino M, Frigo F, Bartolomeoli I, Maifreni M (2011) Safetyrelated properties of staphylococci isolated from food and food environments. J Appl Microbiol 110:550-561. doi:10.1111/j.1365-2672.2010.04909.x

Martineau F, Picard FJ, Ke D, Paradis S, Roy PH, Ouellette M, Bergeron MG (2001) Development of a PCR assay for identification of staphylococci at genus and species levels. J Clin Microbiol 39:2541-2547. doi:10.1128/JCM.39.7.2541-2547.2001

Oliveira M, Bexiga R, Nunes SF, Carneiro C, Cavaco LM, Bernardo F, Vilela CL (2006) Biofilm-forming ability profiling of Staphylococcus aureus and Staphylococcus epidermidis mastitis isolates. Vet Microbiol 118:133-140. doi:10.1016/j.vetmic.2006.07.008

Park JY et al (2011) Comparison of phenotypic and genotypic methods for the species identification of coagulase-negative staphylococ$\mathrm{cal}$ isolates from bovine intramammary infections. Vet Microbiol 147:142-148. doi:10.1016/j.vetmic.2010.06.020

Piette A, Verschraegen G (2009) Role of coagulase-negative staphylococci in human disease. Vet Microbiol 134:45-54. doi:10.1016/j. vetmic.2008.09.009

Poyart C, Quesne G, Boumaila C, Trieu-Cuot P (2001) Rapid and accurate species-level identification of coagulase-negative staphylococci by using the $\operatorname{sodA}$ gene as a target. J Clin Microbiol 39:4296-4301. doi:10.1128/JCM.39.12.4296-4301.2001

Shah MM, Iihara H, Noda M, Song SX, Nhung PH, Ohkusu K, Kawamura Y, Ezaki T (2007) dnaJ gene sequence-based assay for species identification and phylogenetic grouping in the genus Staphylococcus. Int J Syst Evol Microbiol 57:25-30

Sivadon V et al (2005) Use of genotypic identification by $\operatorname{sod} A$ sequencing in a prospective study to examine the distribution of coagulase-negative Staphylococcus species among strains recovered during septic orthopedic surgery and evaluate their significance. J Clin Microbiol 43:2952-2954. doi:10.1128/ JCM.43.6.2952-2954.2005

Svec P, Vancanneyt M, Sedlacek I, Engelbeen K, Stetina V, Swings J, Petras P (2004) Reclassification of Staphylococcus pulvereri Zakrzewska-Czerwinska et al. 1995 as a later synonym of Staphylococcus vitulinus Webster et al. 1994. Int J Syst Evol Microbiol 54:2213-2215

Taponen S, Pyorala S (2009) Coagulase-negative staphylococci as cause of bovine mastitis- not so different from Staphylococcus aureus? Vet Microbiol 134:29-36. doi:10.1016/j. vetmic.2008.09.011

Taponen S, Simojoki H, Haveri M, Larsen HD, Pyorala S (2006) Clinical characteristics and persistence of bovine mastitis caused by different species of coagulase-negative staphylococci identified with API or AFLP. Vet Microbiol 115:199-207. doi:10.1016/j. vetmic.2006.02.001

Tomazi T, Goncalves JL, Barreiro JR, de Campos Braga PA, Prada e Silva LF, Eberlin MN, dos Santos MV (2014) Identification of coagulase-negative staphylococci from bovine intramammary infection by matrix-assisted laser desorption ionization-time of flight mass spectrometry. J Clin Microbiol 52:1658-1663. doi:10.1128/JCM.03032-13

Tremblay YD, Caron V, Blondeau A, Messier S, Jacques M (2014) Biofilm formation by coagulase-negative staphylococci: impact 
on the efficacy of antimicrobials and disinfectants commonly used on dairy farms. Vet Microbiol 172:511-518. doi:10.1016/j. vetmic.2014.06.007

Voytenko AV et al (2006) Identification of Staphylococcus hyicus by polymerase chain reaction mediated amplification of species specific sequences of superoxide dismutase A encoding gene sodA. Vet Microbiol 116:211-216. doi:10.1016/j.vetmic.2006.03.009

Wang $\mathrm{HH}$ et al (2006) Food commensal microbes as a potentially important avenue in transmitting antibiotic resistance genes. FEMS Microbiol Lett 254:226-231. doi:10.1111/j.1574-6968.2005.00030.x

Yugueros J, Temprano A, Berzal B, Sanchez M, Hernanz C, Luengo JM, Naharro G (2000) Glyceraldehyde-3-phosphate dehydrogenase-encoding gene as a useful taxonomic tool for Staphylococcus spp. J Clin Microbiol 38:4351-4355 